\title{
Health-related quality of life and associated factors among epileptic patients on treatment follow up at public hospitals of Wollega zones, Ethiopia, 2018
}

\author{
Muktar Abadiga*, Getu Mosisa, Tadele Amente and Adugna Oluma
}

\begin{abstract}
Objective: The aim of this study was to assess health-related quality of life and its associated factors among epileptic patients in public hospitals of Wollega zones, Ethiopia. Institutional based cross-sectional study was conducted on 402 epileptic patients, from March 01 to March 30, 2018. Multiple linear regression with backward elimination was used, and all analyses were conducted at the 0.05 significance level.

Results: The overall mean total score on the WHOQOL-BREF scale was 60.47 with \pm 23.07 SD. Monthly income $\leq 500 \mathrm{~EB}(\beta=-12.49, P<0.001)$, living alone $(\beta=-7.11, P=0.007)$, adverse drug reaction $(\beta=-10.86$, $P<0.001)$, comorbidity of anxiety $(\beta=-12.99, P<0.001)$, perceived social stigma $(\beta=-9.73, P<0.001)$ and frequency of seizure once per week ( $\beta=-8.41, P=0.001$ ) were negatively associated with quality of life of epileptic patients. The mean quality of life of patients living with epilepsy in this study was low. The clinician should early recognize and treat drug side effects, detect and manage comorbidity, and control seizure in order to increase quality of life of epileptic patients.
\end{abstract}

Keywords: Epilepsy, Quality of life, Wollega zones

\section{Introduction}

Epilepsy is a chronic brain disorder characterized by recurrent seizures [1]. It affects about 50 million people worldwide, and $85 \%$ of them live in developing countries. Its annual incidence is about 50 cases per 100,000 persons in developed countries and 100-190 cases per 100,000 persons in developing countries [2]. The psychosocial effects of epilepsy have led to the need to quantify quality of life in epileptic patients [3]. Quality of life is defined as an individual's perception of their position in life in the context of the culture and value systems in which they live [4]. Quality of life is worse in epileptic patients than in the general population [5]. A crosssectional comparative study done in Kenya showed the

\footnotetext{
*Correspondence: muktarabadiga@gmail.com
}

School of Nursing and Midwifery, Institute of Health Sciences, Wollega

University, Nekemte, Ethiopia mean quality of life among people living with epilepsy $(49.90 \%)$ was significantly $(\mathrm{p}<0.01)$ lower than that of the normal controls $(77.60 \%)$ accompanying them and significantly impaired as compared to the hypothesized mean of $75 \pm 2.5 \%$ [6]. In Ethiopia, $45.8 \%$ of epileptic patients have a poor quality of life [7].

Unpredictable progression of the disease, stigma, poor self-esteem, anxiety and depression, unemployment, social isolation, and cognitive problems has been reported to impair quality of life in epileptic patients [8]. Physical injuries such as burns, drowning, falls, and car accidents can endanger the lives of epileptic patients [9]. The patients may isolate themselves from society because people most often stigmatize them. As a result, they can suffer from depression which may further decrease their quality of life $[10,11]$.

Apart from the disease, the antiepileptic medications can be a burden on the patients. Their side effects such as fatigue, memory problem, difficulty concentrating, and 
drowsiness, difficulty in thinking clearly, and nervousness or agitation affects their quality of life [12]. Their side effects, especially for poly-therapies, have negatively associated with health-related quality of life, independent of seizure frequency [13-16].

However; in Africa and particularly in Ethiopia, few studies have been conducted on the health-related quality of life of epileptic patients [17]. Therefore; this study was aimed to identify factors influencing health-related quality of life of patients with epilepsy in public hospitals of Wollega zones.

\section{Main text \\ Methods \\ Study setting and population}

This study was conducted in six randomly selected hospitals of Wollega zones from March 01 to March 30, 2018. The institutional based cross-sectional study design was employed. All epileptic patients on treatment follow up at selected public hospitals of Wollega zones was the source population and the sampled epileptic patients was the study population. All patients whose ages were 18 years and above were included in the study and persons who are eligible but not willing to take part in the study were excluded from the study.

\section{Sample size determination and sampling techniques}

The sample size of the study was determined using the formula for estimation of a single population proportion. $45.8 \%$ (0.458) proportion of population living with epilepsy who had poor QOL was taken from similar a study done in Addis Ababa [7], and by adding a non-response rate of 5\%, a total of 402 epileptic patients were involved in the study. Simple random sampling method was used to select the study participants.

\section{Data collection tool and procedures}

Data was collected using a structured questionnaire. Quality of Life questionnaire (WHOQOL BREF) scale, Hospital Anxiety and Depression scale (HADS) and stigma scale were used, and face to face interview was employed. WHOQOL-BREF contains 26 items consisting four domains were used: physical health, psychological health, social relationships, and environmental health. Each item of the WHOQOL-BREF was scored from 1 (very dissatisfied/very poor) to 5 (very satisfied/ very good). Each questionnaire is scored on a scale of 24 to 120 , with a higher WHOQOL score indicating better quality of life.

\section{Data processing and analysis}

The data were coded, cleaned and entered into Epi data version 3.1 and exported into SPSS window version 20.0 for analysis. Descriptive statistics were expressed in frequency, percentage, mean and standard deviation. Simple linear regression was used to find an association between dependent variable and each independent variable. Multiple linear regression with backward elimination was used to identify independent factors which best predict quality of life. All analyses were conducted at the $0.05 \mathrm{sig}$ nificance level.

\section{Data quality control}

The questionnaire was translated to the local language and then translated back to English by expertise to check for consistency. Five percent of the questionnaire was pre-tested on epileptic patients at the same study area 5 days before data collection, and some modification of the questionnaire were made. One-day training was given for data collectors and supervisors on how to collect and handle the data.

\section{Results}

Socio-demographic characteristics of the respondents Of the total of 402 study participants sampled, 392 were participated; with a response rate of $97.5 \%$. From the total of 392 participants, $203(51.8 \%)$ were male, and $189(48.2 \%)$ were females. The mean age of the study participant was 30.7 years with \pm 10.04 standard deviation. Majority of the study participant was unmarried, $226(57.7 \%)$ followed by married, which accounts 145 (37.0\%). Concerning educational status, 108 (27.6\%) were completed grade 9-10, 105 (26.8\%) were completed grade $1-8$ and $71(18.1 \%)$ have degree and above. Regarding monthly income, 124 (31.6\%) gets monthly income 501-1000 EB followed by monthly income greater than 2000 EB which accounts 99 (25.3\%); whereas the mean monthly income was $1490.72 \pm 1183.5$ SD. Concerning living condition, 333 (84.9\%) live with parents (Table 1).

\section{Clinical characteristics of the respondents}

Concerning the disease duration, 148 (37.8\%) had duration of $>10$ years, followed by $6-10$ years $(28.8 \%)$. Regarding the type of epilepsy, almost half of the study participants had a focal type which is 199 (50.8\%). Majority of the study participants, $210(53.6 \%)$ had no adverse drug reaction, and 182 (46.4\%) had experienced an adverse drug reaction. Regarding co-morbidity, 116 (29.6\%) had anxiety, and 46 (11.7\%) had depression. One hundred thirty-two, (33.7\%) had perceived stigma, and $313(79.8 \%)$ had a fear of having a seizure. Out of the total respondents, $163(41.6 \%)$ had one seizure attacks per week followed by one seizure attacks per month, 133 (33.9\%) (Table 1). 
Table 1 Distribution of participants by socio-demographic and clinical characteristics at public hospitals of Wollega zone, 2018 ( $n=392)$

\begin{tabular}{|c|c|c|}
\hline Variables & Frequency & Percentage \\
\hline \multicolumn{3}{|l|}{ Gender } \\
\hline Female & 189 & 48.2 \\
\hline Male & 203 & 51.8 \\
\hline \multicolumn{3}{|l|}{ Ethnicity } \\
\hline Oromo & 320 & 81.6 \\
\hline Amhara & 54 & 13.8 \\
\hline Gurage & 5 & 1.3 \\
\hline Tigre & 4 & 1.0 \\
\hline Others & 9 & 2.3 \\
\hline Total & 392 & 100 \\
\hline \multicolumn{3}{|l|}{ Age } \\
\hline $18-24$ & 125 & 31.9 \\
\hline $25-34$ & 147 & 37.5 \\
\hline $35-44$ & 68 & 17.3 \\
\hline$\geq 45$ & 52 & 13.3 \\
\hline Total & 392 & 100 \\
\hline \multicolumn{3}{|l|}{ Religion } \\
\hline Muslim & 42 & 10.7 \\
\hline Orthodox & 89 & 22.7 \\
\hline Protestant & 226 & 57.7 \\
\hline Catholic & 27 & 6.9 \\
\hline Others & 8 & 2.0 \\
\hline Total & 392 & 100 \\
\hline \multicolumn{3}{|l|}{ Marital status } \\
\hline Married & 145 & 37.0 \\
\hline Unmarried & 226 & 57.7 \\
\hline Widowed & 11 & 2.0 \\
\hline Divorced & 10 & 2.6 \\
\hline Total & 392 & 100 \\
\hline \multicolumn{3}{|l|}{ Educational status } \\
\hline No formal education & 44 & 11.2 \\
\hline Grade 1-8 & 105 & 26.8 \\
\hline Grade 9-10 & 108 & 27.6 \\
\hline Diploma & 64 & 16.3 \\
\hline Degree and above & 71 & 18.1 \\
\hline Total & 392 & 100 \\
\hline \multicolumn{3}{|l|}{ Occupational status } \\
\hline Gov't employee & 68 & 17.3 \\
\hline Student & 61 & 15.6 \\
\hline Farmer & 147 & 37.5 \\
\hline Merchant & 69 & 17.6 \\
\hline Daily laborers & 36 & 9.2 \\
\hline Others & 11 & 2.8 \\
\hline Total & 392 & 100 \\
\hline \multicolumn{3}{|l|}{ Residence } \\
\hline Urban & 66 & 16.8 \\
\hline Rural & 326 & 83.2 \\
\hline Total & 392 & 100 \\
\hline
\end{tabular}

Table 1 (continued)

\begin{tabular}{|c|c|c|}
\hline Variables & Frequency & Percentage \\
\hline \multicolumn{3}{|l|}{ Monthly income } \\
\hline$\leq 500$ & 67 & 17.1 \\
\hline $501-1000$ & 124 & 31.6 \\
\hline $1001-1500$ & 68 & 17.3 \\
\hline $1501-2000$ & 34 & 8.7 \\
\hline$\geq 2001$ & 99 & 25.3 \\
\hline Total & 392 & 100 \\
\hline \multicolumn{3}{|c|}{ Duration of disease (years) } \\
\hline$<2$ & 25 & 6.4 \\
\hline $2-5$ & 106 & 27.0 \\
\hline $6-10$ & 113 & 28.8 \\
\hline$>10$ & 148 & 37.8 \\
\hline Total & 392 & 100 \\
\hline \multicolumn{3}{|l|}{ Type of epilepsy } \\
\hline Generalized & 193 & 49.2 \\
\hline Focal & 199 & 50.8 \\
\hline Total & 392 & 100 \\
\hline \multicolumn{3}{|l|}{ Type of therapy } \\
\hline Monotherapy & 260 & 66.3 \\
\hline Polytherapy & 132 & 33.7 \\
\hline Total & 392 & 100 \\
\hline \multicolumn{3}{|c|}{ Adverse drug reaction } \\
\hline Yes & 182 & 46.4 \\
\hline No & 210 & 53.6 \\
\hline Total & 392 & 100 \\
\hline \multicolumn{3}{|c|}{ Co-morbidity of anxiety } \\
\hline Yes & 116 & 29.6 \\
\hline No & 276 & 70.4 \\
\hline Total & 392 & 100 \\
\hline \multicolumn{3}{|c|}{ Co-morbidity of depression } \\
\hline Yes & 46 & 11.7 \\
\hline No & 346 & 88.3 \\
\hline Total & 392 & 100 \\
\hline \multicolumn{3}{|c|}{ Perceived social stigma } \\
\hline Yes & 132 & 33.7 \\
\hline No & 260 & 66.3 \\
\hline Total & 392 & 100 \\
\hline \multicolumn{3}{|l|}{ Frequency of seizure } \\
\hline One per week & 163 & 41.6 \\
\hline One per month & 133 & 33.9 \\
\hline One per year & 60 & 15.3 \\
\hline None in past year & 36 & 9.2 \\
\hline Total & 392 & 100 \\
\hline
\end{tabular}

Whoqol-bref (0-100) characteristics of respondents Descriptive statistics were performed to find out means and standard deviations of WHOQOL measurement scale. The WHOQOL BREF covers four different domains of quality of life, physical, psychological, social 
and environmental. The mean score for physical dimension is $17.89 \pm 6.5 \mathrm{SD}$ with a range of 8 to 32 . The mean score for the Psychological dimension is $15.33 \pm 6.17$ SD with a range of 7 to 27 . The mean score of social dimensions is $7.69 \pm 3.24 \mathrm{SD}$ with a range of 3 to 12 . The mean score for environmental dimension is $19.56 \pm 7.23 \mathrm{SD}$ with a range of 9 to 34 . The overall mean total score on the WHOQOL-BREF scale is 60.47 with \pm 23.14 standard deviation. The minimum score of this WHOQOL BREF in this study is 27.00 and the maximum score is 105.00 with the range of score 78.00 (Additional file 1: Table S1).

\section{Bivariable linear regression analysis}

Simple linear regression analysis was done to investigate how much each independent variable were associated with quality of life. In simple linear regression analysis, socio-demographic variables such as marital status, educational status, occupation, residence, living condition and monthly income showed significant association with quality of life. Clinical variables such as duration of disease, adverse drug reaction, co-morbidity of anxiety, comorbidity of depression, perceived social stigma and frequency of seizure were also showed significant association with health-related quality of life (Table 2).

\section{Multivariable linear regression analysis}

Multivariable linear regression was conducted to examine the best combination of factors for predicting quality of life. So, multivariable linear regressions model with backward elimination was used to extract factors that best predict quality of life. In the final model of multivariable linear regression, monthly income, living condition, adverse drug reaction, co-morbidity of anxiety, perceived social stigma and frequency of seizures were significantly associated with health-related quality of life. Multivariable linear regression analyses showed that monthly income $\leq 500 \mathrm{~EB}, 501-1000 \mathrm{~EB}$ and 1001-1500 EB were negatively associated with health-related quality of life $(\beta=-12.49, \mathrm{P}<0.001, \beta=-10.10, \mathrm{P}<0.001$ and $\beta=-8.41, P=0.012$ respectively) when compared with monthly income $>2000$ EB. The finding also showed that living alone were negatively associated with healthrelated quality of life $(\beta=-7.11, P=0.007)$ when compared with those who live with their parents.

Presence of adverse drug reaction was negatively associated with health-related quality of life $(\beta=-10.86$, $\mathrm{P}<0.001)$. The result also showed that comorbidity of anxiety was negatively influenced health related quality of life $(\beta=-12.99, P<0.001)$. Presence of social stigma was negatively associated with health-related quality of life $(\beta=-9.73, P<0.001)$, and the frequency of seizure once per week showed negative association with healthrelated quality of life of epileptic patients $(\beta=-8.4$,
$\mathrm{P}=0.001$ ). In the multivariable regression, the model is significant $(\mathrm{F}=20.42, P$ value $<0.001)$ and has an adjusted $R^{2}=0.458$. The adjusted $R^{2}$ of $0.458(45.8 \%)$ of this model indicates that the variables included in the model explain about $45.8 \%$ of the variance or change in quality of life (Table 3).

\section{Discussion}

In this study, we estimated the quality of life of peoples living with epilepsy. The result showed that the mean quality of life is $60.47 \pm 23.07 \mathrm{SD}$. The mean quality of life of in this study is similar with a study done in Uganda [18] and Addis Ababa [7]. However; the mean quality of life in the present study is lower than a study done in India [19] and Malaysia [24]. On the other hand, the mean quality of life of this study is higher than the study done in Russia [20] and Australia [25]. The possible reason for the discrepancy might be due to inadequate sample size and non-random sampling techniques in Russian study. The other possible reason could be this cross-sectional study was conducted using WHOQOL-BREF, but others were conducted using the Quality of Life Inventory for Epilepsy (QOLIE-31).

In this study, respondent's monthly income was significantly associated with health-related quality of life, which is in line with a study done in Kenya [6] and in Addis Ababa at Amanuel Mental Specialized Hospital [7]. The finding of this study showed that adverse drug reaction was associated with quality of life of epileptic patients. This finding is consistent with a study done in Uganda [18], India [19] and Russia [20]. The finding of this study also showed that co-morbidity of anxiety was associated with quality of life of epileptic patients which is supported by a study done in Addis Ababa [7].

Moreover, in this study, most of the respondents who had frequent seizures reported the poor quality of life. This finding is consistent with many previous studies conducted in different parts of the world [7, 18-23]. This finding is also consistent with a study done in Kenya [6] and Malaysia [24] and Australia [25]. The results of the present study also revealed that the HRQOL is significantly influenced by stigmatization about their disease, which is similar with a study done in Addis Ababa [7] and Australia [25]. Unlike to other studies, age, marital status, educational level and gender were not significantly associated with health-related quality of life.

\section{Conclusion}

The mean health-related quality of life of people living with epilepsy in this study was low. Respondent's monthly income, living condition, adverse effects of antiepileptic medications, co-morbidity of anxiety, perceived stigma, and frequency of seizure have significantly affected the 
Table 2 Simple linear regression analysis of factors associated with Quality of life among epileptic patients attending public hospitals of Wollega zones, West Ethiopia, 2018

\begin{tabular}{|c|c|c|c|c|c|}
\hline \multirow[t]{2}{*}{ Variables } & \multicolumn{2}{|c|}{ Unstandardized coefficient } & \multirow{2}{*}{$\begin{array}{l}\text { Standardized coefficient } \\
\text { Beta }\end{array}$} & \multirow[t]{2}{*}{$\mathrm{t}$ value } & \multirow[t]{2}{*}{ P-value } \\
\hline & Beta & Standard error & & & \\
\hline \multicolumn{6}{|l|}{ Gender } \\
\hline Female vs male & -2.49 & 2.33 & -0.05 & -1.07 & 0.28 \\
\hline \multicolumn{6}{|l|}{ Ethnicity } \\
\hline Amhara vs Oromo & 2.40 & 10.42 & 0.01 & 0.23 & 0.81 \\
\hline Gurage vs Oromo & -6.8 & 11.63 & -0.03 & -0.58 & 0.55 \\
\hline Tigre vs Oromo & -3.59 & 7.80 & -0.02 & -0.46 & 0.64 \\
\hline \multicolumn{6}{|l|}{ Religion } \\
\hline Muslim vs protestant & -0.27 & 3.71 & -0.005 & -0.07 & 0.94 \\
\hline Orthodox vs protestant & 1.24 & 3.18 & 0.02 & 0.39 & 0.69 \\
\hline Catholic vs protestant & 4.40 & 8.64 & 0.02 & 0.50 & 0.61 \\
\hline \multicolumn{6}{|l|}{ Educational status } \\
\hline No formal education vs $\geq$ degree & -8.66 & 3.07 & -0.16 & -2.81 & 0.005 \\
\hline Grade $1-8$ vs $\geq$ degree & -10.39 & 3.05 & -0.20 & -3.40 & 0.001 \\
\hline Grade $9-10$ vs $\geq$ degree & -7.87 & 3.55 & -0.12 & -2.21 & 0.027 \\
\hline \multicolumn{6}{|l|}{ Occupation } \\
\hline Student vs Gov't employee & -10.12 & 2.72 & -0.21 & -3.71 & $<0.001$ \\
\hline Farmer vs Gov't employee & -3.91 & 3.37 & -0.06 & -1.15 & 0.24 \\
\hline Merchant vs Gov't employee & -14.30 & 4.26 & -0.17 & -3.35 & 0.001 \\
\hline Daily laborers vs Gov't employee & -1.21 & 7.10 & -0.009 & -0.17 & 0.86 \\
\hline \multicolumn{6}{|l|}{ Marital status } \\
\hline Unmarried vs married & -11.59 & 7.00 & -0.08 & -1.70 & 0.08 \\
\hline Widowed vs married & -16.73 & 7.34 & -0.11 & -2.27 & 0.02 \\
\hline \multicolumn{6}{|l|}{ Residence } \\
\hline Urban vs rural & 8.70 & 3.08 & 0.14 & 2.82 & 0.005 \\
\hline \multicolumn{6}{|l|}{ Monthly income } \\
\hline$\leq 500$ vs $>2000 \mathrm{~EB}$ & -16.81 & 2.60 & -0.33 & -6.44 & $<0.001$ \\
\hline $501-1000$ vs $>2000 E B$ & -10.12 & 3.16 & -0.16 & -3.20 & 0.001 \\
\hline $1001-1500$ vs $>2000$ EB & -10.58 & 4.13 & -0.12 & -2.55 & 0.011 \\
\hline \multicolumn{6}{|l|}{ Living condition } \\
\hline Alone vs with parents & -15.65 & 3.16 & -0.24 & -4.94 & $<0.001$ \\
\hline \multicolumn{6}{|l|}{ Type of epilepsy } \\
\hline Generalized vs focal & 0.65 & 2.33 & 0.01 & 0.28 & 0.77 \\
\hline \multicolumn{6}{|l|}{ Adverse drug reaction } \\
\hline Yes vs no & -18.49 & 2.14 & -0.40 & -8.62 & $<0.001$ \\
\hline \multicolumn{6}{|l|}{ Co-morbidity of anxiety } \\
\hline Yes vs no & -21.02 & 2.32 & -0.41 & -9.04 & $<0.001$ \\
\hline \multicolumn{6}{|l|}{ Co-morbidity of depression } \\
\hline Yes vs no & -22.35 & 3.44 & -0.31 & -6.48 & $<0.001$ \\
\hline \multicolumn{6}{|l|}{ Fear of having seizure } \\
\hline Yes vs no & -4.78 & 2.89 & -0.08 & -1.65 & 0.100 \\
\hline \multicolumn{6}{|l|}{ Perceived social stigma } \\
\hline Yes vs no & -13.04 & 2.38 & -0.26 & -5.48 & $<0.001$ \\
\hline Age at onset of disease & & & & & \\
\hline $10-19$ years vs $<10$ years & 0.13 & 2.87 & 0.002 & 0.04 & 0.96 \\
\hline $20-29$ years vs $<10$ years & 7.40 & 3.95 & 0.09 & 1.87 & 0.06 \\
\hline$\geq 40$ years vs $<10$ years & 2.33 & 9.52 & 0.01 & 0.24 & 0.80 \\
\hline Frequency of seizure & & & & & \\
\hline One per year vs none in past year & -8.34 & 2.53 & -0.17 & -3.29 & 0.001 \\
\hline One per month vs none in past year & -19.20 & 3.27 & -0.30 & -5.82 & $<0.001$ \\
\hline One per week vs none in past year & -23.11 & 3.98 & -0.29 & -5.79 & $<0.001$ \\
\hline
\end{tabular}

Predictor variables: Sociodemographic and clinical variables. Dependent variables: health related quality of life 
Table 3 Ordinary least square regression analysis of factors associated with quality of life among epileptic patients attending public hospitals of Wollega zones, West Ethiopia, 2018

\begin{tabular}{|c|c|c|c|c|c|c|c|}
\hline \multirow[t]{2}{*}{ Variables } & \multicolumn{2}{|c|}{ Unstandardized coefficient } & \multirow{2}{*}{$\begin{array}{l}\text { Standardized } \\
\text { coefficient } \\
\text { Beta }\end{array}$} & \multirow[t]{2}{*}{ t value } & \multirow[t]{2}{*}{ P-value } & \multicolumn{2}{|c|}{$\begin{array}{l}\text { Multicollinearity } \\
\text { statistics }\end{array}$} \\
\hline & Beta & Standard error & & & & Tolerance & VIF \\
\hline \multicolumn{8}{|l|}{ Monthly income } \\
\hline$\leq 500$ vs $>2000 \mathrm{~EB}$ & -12.49 & 2.19 & -0.25 & -5.70 & $<0.001$ & 0.71 & 1.40 \\
\hline $501-1000$ vs $>2000$ EB & -10.10 & 2.63 & -0.16 & -3.83 & $<0.001$ & 0.74 & 1.34 \\
\hline $1001-1500$ vs $>2000$ EB & -8.41 & 3.33 & -0.10 & -2.52 & 0.012 & 0.83 & 1.19 \\
\hline \multicolumn{8}{|l|}{ Living condition } \\
\hline Alone vs with parents & -7.11 & 2.63 & -0.11 & -2.70 & 0.007 & 0.83 & 1.20 \\
\hline \multicolumn{8}{|l|}{ Adverse drug reaction } \\
\hline Yes vs no & -10.86 & 1.83 & -0.23 & -5.92 & $<0.001$ & 0.88 & 1.13 \\
\hline \multicolumn{8}{|l|}{ Co-morbidity of anxiety } \\
\hline Yes vs no & -12.99 & 2.03 & -0.25 & -6.39 & $<0.001$ & 0.85 & 1.16 \\
\hline \multicolumn{8}{|l|}{ Perceived social stigma } \\
\hline Yes vs no & -9.73 & 1.94 & -0.20 & -5.00 & $<0.001$ & 0.87 & 1.14 \\
\hline \multicolumn{8}{|l|}{ Frequency of seizure } \\
\hline One per week vs none in past year & -8.41 & 2.52 & -0.13 & -3.33 & 0.001 & 0.89 & 1.12 \\
\hline
\end{tabular}

Intercept $($ constant $)=42.15$; standard error $=3.62$; $\mathrm{t}$-value $=11.63$; sig. $<0.001$; adjusted $\mathrm{R}$ square $=0.458(45.8 \%), \mathrm{F}=20.42, \mathrm{P}<0.001$. Dependent variables: health related quality of life

quality of life of epileptic patients. The clinician should early recognize and treat drug side effects, early detect and manage comorbidity, and control seizure in order to increase quality of life of epileptic patients.

\section{Limitation of the study}

The research design is cross-sectional in nature and cannot confirm causality.

\section{Supplementary information}

Supplementary information accompanies this paper at https://doi. org/10.1186/s13104-019-4720-3

Additional file 1: Table S1. Means and standard deviation of overal $\mathrm{HRQOL}$ and its subscale/dimension scores among epileptic patients attending public hospitals of Wollega Zones, West Ethiopia, 2018.

\section{Abbreviations}

ADRs: adverse drug reactions; AEDs: anti-epileptic drugs; HADS: Hospital Anxiety and Depression Scales; HRQOL: health related quality of life; QOL: quality of life; QOLIE: quality of life in epilepsy inventory; SPSS: Statistical Package for Social Science; PWE: people with epilepsy; WHO: World Health Organization; WHOQOL: World Health Organization Quality Of Life.

\section{Acknowledgements}

We would like to acknowledge Wollega University for financial support. We are also grateful to the study participants who voluntarily agreed to be interviewed and participated in the study.

\section{Authors' contributions}

MA involved in conceptualization of the study, designing, result writing and analyzing the finding. GM involved in designing of the study and revising a manuscript. TA participated in result writing and analyzing the finding.
AO involved in writing and revising the manuscript. All authors read and approved the final manuscript.

Funding

The research was funded by Wollega University. The funding organization has no role in the design of the study, data collection, analysis, and interpretation of the data and writing the manuscript.

\section{Availability of data and materials}

The data used during the current study are available from the corresponding author on request.

Ethical approval and consent to participate

The study was reviewed and approved by the Institutional Review Boards of Wollega University Ethical review board. Written informed consent was obtained from the study participants before data collection.

\section{Consent for publication}

Not applicable.

Competing interests

The authors declare that they have no competing interests.

Received: 3 April 2019 Accepted: 12 October 2019

Published online: 22 October 2019

\section{References}

1. WHO. Atlas: epilepsy care in the world. Geneva: World Health Organization Press; 2005

2. Leonardi M, Ustun TB. The global burden of epilepsy. Epilepsia. 2002;43(Suppl6):21-5

3. Jacoby A. Epilepsy and the quality of everyday life: findings from a study of people with well-controlled epilepsy. Soc Sci Med. 1992;34:657-66. 
4. WHO. Division of mental health and prevention of substance abuse: WHOQOL user manual. Geneva: WHO; 1998.

5. Wagner AK, Bungay KM, Kosinski M, Bromfield EB, Ehrenberg BL. The health status of adults with epilepsy compared with that of people without chronic conditions. Pharmacotherapy. 1996;16(1):1-9.

6. Kinyanjui, et al. Quality of life among patients living with epilepsy attending the neurology clinic at kenyatta national hospital, Nairobi, Kenya: a comparative study. Health Qual Life Outcomes. 2013;11:98.

7. Tegegne MT, Muluneh NY, Wochamo TT, Awoke AA, Mossie TB, Yesigat MA. Assessment of quality of life and associated factors among people with epilepsy attending at Amanuel Mental Specialized Hospital, Addis Ababa. Ethiopia. Sci J Public Health. 2014;2(5):378-83.

8. Baker GA. Assessment of quality of life in people with epilepsy: some practical implications. Epilepsia. 2001;42(Suppl 3):66-9.

9. Raty LK, Wilde Larsson BM. Quality of life in young adults with uncomplicated epilepsy. Epilepsy Behav. 2007;10(1):142-7.

10. Smeets VM, van Lierop BA, Vanhoutvin JP, Aldenkamp AP, Nijhuis FJ. Epilepsy and employment: literature review. Epilepsy Behav. 2007;10(3):354-62.

11. Christensen J, Vestergaard M, Mortensen PB, Sidenius P, Agerbo E. Epilepsy and risk of suicide: a population-based case-control study. Lancet Neurol. 2007;6(8):693-8.

12. Baker GA, Jacoby A, Buck D, Stalgis C, Monnet D. Quality of life of people with epilepsy: a European study. Epilepsia. 1997;38(3):353-62.

13. Gilliam F. Optimizing health outcomes in active epilepsy. Neurology. 2002;58(8 Suppl 5):S9-20.

14. Jacoby A. Stigma, epilepsy, and quality of life. Epilepsy Behav. 2002;3(6S2):10-20.

15. Johnson EK, Jones JE, Seidenberg S, Hermann BP. The relative impact of anxiety, depression, and clinical seizure features on health-related quality of life in epilepsy. Epilepsia. 2004:45(5):544-50.

16. Cramer JA. Mood disorders are linked to health-related quality of life in epilepsy. Epilepsy Behav. 2002;6(3):491-2.
17. Chin $\mathrm{JH}$. Epilepsy treatment in sub-Saharan Africa: closing the gap. Afr Health Sci. 2012;12(2):186-92.

18. Nabukenya, et al. Health-related quality of life in epilepsy patients receiving anti-epileptic drugs at National Referral Hospitals in Uganda: a cross-sectional study. Health Qual Life Outcomes. 2014;12:49.

19. Jesse $G$, et al. Antiepileptic drugs and quality of life in patients with epilepsy: a tertiary care hospital-based study. Value Health Reg Issues. 2015;6:1-6

20. Guekht Alla B, et al. Factors influencing on quality of life in people with epilepsy. Seizure. 2007;16:128-33.

21. Baker GA, Gagnon D, McNulty P. The relationship between seizure frequency, seizure type and quality of life: findings from three European countries. Epilepsy Res. 1998;30(3):231-40.

22. Hela M, Amel M, Bechir $Z$, et al. Health related quality of life of people with epilepsy compared with a general reference population. A Tunisian study. Epilepsia. 2004;45:838-43.

23. Edefonti et al. Health-related quality of life in adults with epilepsy: the effect of age, age at onset and duration of epilepsy in a multicentre Italian study. BMC Neurol. 2011;11:33 http://www.biomedcentral. com/1471-2377/11/33

24. Norsa'adah et al. The quality of life of people with epilepsy at a tertiary referral centre in Malaysia. Health Qual Life Outcomes. 2013;11:143. http://www.hqlo.com/content/11/1/143.

25. McLaughlin DP, Pachana NA, Mcfarland K. Stigma, seizure frequency and quality of life: the impact of epilepsy in late adulthood. Seizure. 2008;17(3):281-7.

\section{Publisher's Note}

Springer Nature remains neutral with regard to jurisdictional claims in published maps and institutional affiliations.
Ready to submit your research? Choose BMC and benefit from:

- fast, convenient online submission

- thorough peer review by experienced researchers in your field

- rapid publication on acceptance

- support for research data, including large and complex data types

- gold Open Access which fosters wider collaboration and increased citations

- maximum visibility for your research: over $100 \mathrm{M}$ website views per year

At $\mathrm{BMC}$, research is always in progress.

Learn more biomedcentral.com/submissions 